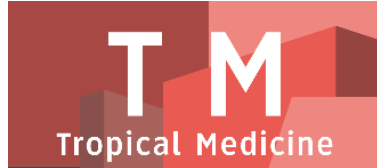

PAPER - OPEN ACCESS

\title{
Mikroenkapsulasi Metronidazol Menggunakan Hemiselulosa Tongkol Jagung (Zea Mays L.) Dengan Metode Gelasi Ionik
}

Author

DOI

: Gabena Indrayani Dalimunthe

Electronic ISSN

: 10.32734/tm.v1i3.264

Print ISSN

$$
\text { : 2623-0542 }
$$$$
\text { : 2623-0550 }
$$

Volume 1 Issue 3 - 2018 TALENTA Conference Series: Tropical Medicine (TM)

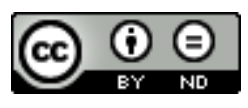

This work is licensed under a Creative Commons Attribution-NoDerivatives 4.0 International License.

Published under licence by TALENTA Publisher, Universitas Sumatera Utara
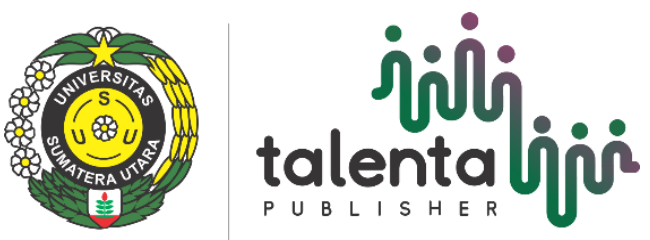


\title{
Mikroenkapsulasi Metronidazol Menggunakan Hemiselulosa Tongkol Jagung (Zea Mays L.) Dengan Metode Gelasi Ionik
}

\author{
Gabena Indrayani Dalimunthe $\mathrm{a}^{\mathrm{a}^{*}}$, Muchlisyam $^{\mathrm{b}}$ \\ ${ }^{a}$ Fakultas Matematika dan Ilmu Pengetahuan Alam, Universitas Muslim Nusantara Al Washliyah \\ ${ }^{\mathrm{b}}$ Fakultas Farmasi Universitas Sumatera Utara \\ gabenaindrayani@yahoo.co.id
}

\begin{abstract}
Abstrak
Pengembangan inovasi bentuk sediaan farmasi yang dapat menunda pelepasan obat merupakan hal yang mempunyai peluang besar, misalnya bentuk sediaan farmasi dengan teknologi penyalutan. Contoh yang penting dari bentuk sediaan ini adalah sediaan mikroenkapsulasi dalam bentuk mikropartikel. Pemanfaatan limbah tongkol jagung yang mengandung hemiselulosa tinggi, dapat dibuat menjadi sediaan mikropartikel yang berfungsi sebagai (carier) obat, selama ini belum pernah dilakukan. Alasan lain pemanfaatan tongkol jagung masih sangat terbatas, pada umumnya hanya sebagai bahan pangan ternak dan bahan bakar. Sifat hemiselulosa yang non toksik mukoadhesif, biodegradabel, biokompatibel serta tingkat imunogenitas yang rendah juga adalah salah satu kriteria yang sangat baik dijadikan sebagai carier obat. Tujuan penelitian ini adalah untuk membuat sediaan mikropartikel menggunakan metode gelasi ionik dengan variasi berat dari hemiselulosa tongkol jagung dengan model obat metronidazole dan untuk melihat evaluasi serta karakteristik mikropartikel hemiselulosa tongkol jagung. Mikropartikel hemiselulosa dibuat dengan metode gelasi ionik yang memiliki keuntungan yaitu karena prosesnya yang sederhana, tidak menggunakan pelarut organik, dan pembuatannya dapat dikontrol. Proses pembentukan partikel terjadi karena adanya kompleksasi akibat muatan yang berbeda antara polisakarida dan counter ion sehingga mengalami gelasi ionik dan presipitasi membentuk partikel yang sferis. Sediaan dibagi menjadi lima, formula dengan variasi hemiselulosa (F1)100mg, (F2)200mg, (F3)300mg, (F4)400mg dan (F5) 500mg. Evalusi terhadap mikropartikel hemiselulosa meliputi: organoleptik, uji kelarutan mikropartikel, uji distribusi ukuran partikel (Uji PSA), Uji SEM,dan uji FTIR. Mikropartikel yang terbentuk dengan metode gelasi ionik menunjukkan hasil organoleptis yaitu bentuk serbuk, warna coklat muda, tidak berasa, tidak berbau. Hasil uji kelarutan menuknjukkan bahwa hemiselulosa mudah larut dalam suasana alkali $(\mathrm{NaOH} 0,1 \mathrm{~N})$. Pengukuran mikropartikel dilakukan dengan PSA (Particle Size Analyzer) menunjukkan bahwa F(1) memiliki ukuran partikel yang terkecil yaitu :0,45336 $\mu \mathrm{m}, \mathrm{F}(2): 0,63593 \mu \mathrm{m}, \mathrm{F}(3): 0,71732 \mu \mathrm{m}, \mathrm{F}(4): 0,89322 \mu \mathrm{m}$ dan $\mathrm{F}(5): 0,91857$ $\mu \mathrm{m}$. Data FTIR menujukkan mikropartikel hemiselulosa memiliki gugus fungsi : $\mathrm{OH}, \mathrm{CH}, \mathrm{C}=\mathrm{O}, \mathrm{C}-\mathrm{OH}, \mathrm{C}-\mathrm{C}$, Sedangkan hasil SEM menunjukkan bahwa bentuk partikel yang diperoleh berupa partikel kecil yang berpori yang memberikan gambran tentang sifat alir dan pelepasan zat aktif yang baik dalam proses enkapsulasi. Hasil yang diperoleh menunjukkan bahwa metode gelasi ionik merupkan metode yang baik dalam membuat mikropartikel dan hemiselulosa tongkol jagung dapat dibuat mikropartikel yang baik dan telah memenuhi evaluasi dan karakteristik yang standar dibandingkan dengan hemiselulosa yang ada dipasaran (buatan pabrik). Hasil SEM membuktikan bahwa ukuran partikel adalah mikropartikel yang memiliki pori sehingga baik digunakan sebagai sediaan mikroenkapsulasi.
\end{abstract}

Kata kunci : mikropartikel, hemiselulosa, metronidazole, tongkol jagung

\begin{abstract}
The development of innovations in pharmaceutical preparations that can delay the release of drugs is a great opportunity, such as the form of pharmaceutical preparations with coating technology. An important example of this dosage form is microencapsulated preparations in the form of microparticles. Utilization of corncob wastes containing high hemicellulose, can be made into microparticle preparations that serve as drug (carier), has never been done. Another reason for the utilization of corn cobs is still very limited, generally only as food for livestock and fuel. The non-toxic, mucoadhesive, biodegradable, biocompatible and low
\end{abstract}


immunogenic hemicellulose properties are also one of the most well-established criteria for drug placement. The objective of this study was to make microparticle preparations using ionic gelation method with weight variation from corncob hemicellulose with metronidazole drug model and to see evaluation and characteristics of corncob hemicellulose microparticles. The hemicellulosic microparticles are made by ionic gelation having the advantage of being simple, not using organic solvents, and their manufacture can be controlled. The process of particle formation occurs because of the complexity due to different charges between the polysaccharide and the ion counter so that it undergoes ionic gelation and precipitation forms spherical particles. The preparation is divided into five, formulas with variations of hemicellulose (F1) 100mg, (F2) 200mg, (F3) 300mg, (F4) 400mg and (F5) 500mg. Evaluations of hemicellulosic microparticles include: organoleptic, microparticle solubility test, particle size distribution test (PSA Test), SEM Test, and FTIR test. Microparticles formed by the ionic gelation method show organoleptic results of powder form, light brown, tasteless, odorless. The results of the solubility test show that the hemicellulose is easily soluble in an alkaline atmosphere $(\mathrm{NaOH} 0.1 \mathrm{~N})$. Microparticle measurements performed with PSA (Particle Size Analyzer) showed that F (1) had the smallest particle size: $0.45336 \mu \mathrm{m}, \mathrm{F}(2): 0.63593 \mu \mathrm{m}, \mathrm{F}(3): 0.71732 \mu \mathrm{m}, \mathrm{F}(4): 0.89322 \mu \mathrm{m}$ and F (5): $0.91857 \mu \mathrm{m}$. The FTIR data showed that the hemicellulosic microparticles had a functional group: $\mathrm{OH}, \mathrm{CH}, \mathrm{C}=\mathrm{O}, \mathrm{C}-\mathrm{OH}, \mathrm{CC}$, whereas the SEM results showed that the particle shape obtained was a small, porous particle giving the image of the flow properties and the release of a good active substance in encapsulation process.

The results show that ionic gelation method is a good method of making microparticles and corncob hemicellulose can be made good microparticles and has met the standard evaluation and characteristics compared to the hemicellulose in the market (manufactured). The SEM results show that the particle size is a microparticle that has a pore so that it is both used as a microencapsulated preparation.

Keywords: microparticles, hemicellulose, metronidazole, corncobs.

\section{Pendahuluan}

Pengembangan inovasi bentuk sediaan farmasi yang dapat menunda pelepasan obat merupakan hal yang mempunyai peluang besar, misalnya bentuk sediaan farmasi dengan teknologi penyalutan. Contoh yang penting dari bentuk sediaan ini adalah sediaan mikroenkapsulasi [1]. Mikroenkapsulasi merupakan teknologi yang berkembang pesat karena menawarkan keuntungan dalam berbagai bidang diantaranya bidang farmasi, teknologi pangan dan industri kertas. Enkapsulasi merupakan teknik melindungi suatu material yang dapat berupa komponen bioaktif berbentuk cair, padat, atau gas menggunakan penyalut yang berbentuk lapisan kompleks yang menyelimuti inti dengan ukuran sampai 5000 $\mu \mathrm{m}$. Bahan inti yang dilindungi dalam proses enkapsulasi disebut sebagai core dan struktur yang dibentuk oleh bahan pelindung yang menyelimuti inti disebut dinding, membran atau kapsul [2].

Tongkol jagung mengandung hemiselulosa tertinggi dibanding limbah pertanian lain seperti bagas tebu, sekam, kulit kacang dan kulit biji kapas [3],[4], tongkol jagung juga merupakan bagian terbesar dari limbah jagung, yaitu sekitar 40-50\% dari berat jagung [5], padahal pemanfaatan tongkol jagung masih sangat terbatas, pada umumnya hanya dimanfaatkan sebagai bahan pangan ternak dan bahan bakar [6],[7].

Pemanfaatan limbah tongkol jagung dibuat menjadi sediaan mikropartikel yang berfungsi sebagai (carier) obat, selama ini belum pernah dilakukan. Peneliti terdahulu telah menggunakan chitosan dan chondroitin sebagai matriks, namun dari segi dana bahan ini masih lebih mahal harganya dibandingkan dengan hemiselulosa tongkol jagung yang lebih ekonomis [8]. Alasan lain karena sifat hemiselulosa yang non toksik mukoadhesif, biodegradabel, biokompatibel serta tingkat imunogenitas yang rendah [9], juga adalah salah satu kriteria yang sangat baik dijadikan sebagai carier obat. Tujuan penelitian ini adalah untuk membuat sediaan mikropartikel menggunakan metode gelasi ionik dengan variasi berat dari hemiselulosa tongkol jagung dengan model obat metronidazole dan untuk melihat evaluasi serta karakteristik mikropartikel hemiselulosa tongkol jagung.

Metronidazol adalah salah satu obat pilihan sebagai anti bakteri yang digunakan terutama dalam pengobatan infeksi yang disebabkan oleh organisme yang rentan, terutama bakteri anarob dan protozoa [10]. Pembuatan mikropartikel dengan metode gelasi ionik merupakan metode yang umum digunakan dan banyak menarik perhatian peneliti dikarenakan prosesnya yang sederhana, tidak menggunakan pelarut organik, dan dapat dikontrol dengan mudah untuk formulasi mikropartikel maupun nanopartikel menggunakan polimer polisakarida. Proses pembentukan partikel terjadi karena adanya kompleksasi akibat muatan yang berbeda antara polisakarida dan counter ion sehingga mengalami gelasi ionik dan presipitasi membentuk partikel sferis. 


\section{Bahan dan Metode}

Metode penelitian ini berdasarkan pada metode eksperimental. Meliputi pengumpulan dan pengolahan sampel, karakterissari simplisia, isolasi hemiselulosa, karakteristik hemiselulosa, formulasi hemiselulosa menjadi mikropartikel dengan berbagai konsentrasi (metode gelasi ionik), uji terhadap mikropartikel. Bahan-bahan yang digunakan dalam penelitian ini adalah hemiselulosa tongkol jagung (hasil isolasi), sodium tripolipospat (STTP) (E Merck), propilen glikol/PG (E Merck), metronidazol baku (E Merck), Natrium hidroksida (E Merck), aquadest bebas $\mathrm{CO}_{2}$, aquadest,etanol $70 \%$, asam asetat $0,1 \mathrm{~N}$ ( E Merck).

Terlebih dahulu dilakukan isolasi hemiselulosa dari tongkol jagung, selanjutnya dilakukan karakterisasi hemiselulosa tongkol jagung, selanjutnya hemiselulosa digunakan sebagai peng-enkapsulasi metronidazole.

\subsection{Analisis data}

\subsubsection{Pengujian Organoleptik}

Pengujian organoleptik terdiri dari pengamatan visual, pengujian rasa, pengujian bau dan bentuk. Pengamatan visual dilakukan terhadap tekstur warna dari mikropartikel hemiselulosa yang dihasilkan.

\subsubsection{Uji Kelarutan}

Kelarutan mikropartikel hemiselulosa diuji dengan melarutkan dalam pelarut suasana basa $(\mathrm{NaOH} 0,1 \mathrm{~N})$, asam $(\mathrm{CH} 3 \mathrm{COOH}$ 0,1 N), Air panas dan air dingin, etanol. Kelarutan suatu senyawa menunjukkan seberapa jauh senyawa tersebut dapat larut dalam suatu pelarut.

\subsubsection{Uji Distribusi Ukuran Partikel (PSA)}

Berdasarkan analisis menggunakan alat PSA diperolehakan diperoleh ukuran partikel dari berbagai konsentrasi hemiselulosa.

\subsubsection{Uji SEM (Scan Electro Magnetic) hemiselulosa}

Analisis SEM dilakukan untuk mengetahui struktur morfologi dan porositas permukaan hemiselulosa tongkol jagung. Sampel diletakkan dan ditempel di atas SEM specimen holder. Ruang sampel divakumkan hinga 10-6 torr, kemudian dioperasikan dengan standar parameter operasi [11].

\subsubsection{Analisis Fourier Transform Infra Red ( FTIR)}

Analisis FTIR dilakukan dengan metode pelet KBr. Preparasi sampel dilakukan dengan 1-10 mg sampel dihaluskan dan dicampur dengan $100 \mathrm{mg} \mathrm{KBr}$. Kemudian dicetak menjadi cakram tipis atau pelet lalu dianalisis. Puncak - puncak karakteristik yang nampak pada spektrum FTIR dari hemiselulosa yang diinterpretasi [12].

\subsection{Pembuatan Mikropartikel}

\subsubsection{Rancangan Formulasi mikropartikel}

Formula mikropartikel dibuat dengan memvariasikan konsentrasi hemiselulosa tongkol jagung hasil isolasi yang dikombinasi dengan STTP (sebagai cross lingker), PG (Propilen Glikol).

Tabel 1.1 Formula Mikropartikel

\begin{tabular}{llllll}
\hline Bahan & Formula 1 & Formula 2 & Formula 3 & Formula 4 & Formula 5 \\
\hline $\begin{array}{l}\text { Hemiseluosa tongkol } \\
\text { jagung (mg) }\end{array}$ & 100 & 200 & 300 & 400 & 500 \\
Metronidazol (mg) & 250 & 250 & 250 & & \\
STTP (mg) & 100 & 100 & 100 & 100 & 250 \\
PG (tetes) & 8 & 8 & 8 & 8 & 8 \\
\hline
\end{tabular}




\subsubsection{Pembuatan Mikropartikel Hemiselulosa Tongkol Jagung dengan Metronidazol}

Hemiselulosa tongkol jagung (dengan variasi berat, dimulai dari yang terkecil, yaitu 100mg sampai $500 \mathrm{mg}$ ) dilarutkan dalam $\mathrm{NaOH}$ 0,1 N sebanyak $100 \mathrm{ml}$. (a), selanjutnya dengan perlakuan yang sama hemiselulosa tongkol jagung (dengan variasi berat, dimulai dari yang terkecil, yaitu $100 \mathrm{mg}$ sampai $500 \mathrm{mg}$ ) dilarutkan dalam asam asetat 0,1 N sebanyak $100 \mathrm{ml}$. (b), Selanjutnya dicampurkan bagian (b) kedalam bagian (a) sedikit demi sedikit sampai suasana PH 7,5, selanjutnya distirer selama 2 jam sampai homogen, kemudian ditambahkan tripolipospat (STTP), aduk terus sampai homogen. STTP berfungsi sebagai pentaut silang (crosslinker), Selanjutnya ditambahkan propilen glikol (PG), diaduk homogen

dan ditambahkan metronidazole, diaduk homogen, kemudian disentrifugasi $1000 \mathrm{rpm}$ selama $3 \mathrm{jam}$. Akan terbentuk endapan, kemudian dipisahkan dan dikering anginkan (terbentuk mikropartikel) [13].

\subsubsection{Mikropartikel}

Evaluasi mikropartikel meliputi: uji kelarutan mikropartikel, uji pengukuran ukuran partikel (PSA), penentuan efisiensi penjerapan dalam mikropartikel, faktor perolehan kembali, uji FTIR, dan uji SEM .

\section{Hasil Dan Pembahasan}

Tabel 2. Kelarutan mikropartikel Hemiselulosa

\begin{tabular}{lll}
\hline No & Pelarut & Hasil kelarutan \\
\hline 1 & Basa $(\mathrm{NaOH} 0,1 \mathrm{~N})$ & Larut \\
2 & Asam $\left(\mathrm{CH}_{3} \mathrm{COOH} 0,1 \mathrm{~N}\right)$ & Sukar larut \\
3 & Air panas & Praktis tidak larut \\
4 & Air dingin & Praktis tidak larut \\
\hline
\end{tabular}

Kelarutan suatu senyawa mnunjukkan seberapa jauh senyawa tersebut dapat larut dalam suatu pelarut. Dalam hal ini ditunjukkan bahwa kelarutan hemiselulosa sama dengan kelarutan mikropartikel. Dari analisis kelarutan ini dapat diambil kesimpulan tidak terjadi reaksi kimia antara metronidazol dan hemiselulosa sebagai polimer setelah pembentukan mikrokapsul karena tidak memiliki perbedaan kelarutan pada pelarut yang di uji.

Tabel 3. Hasil Pengujian Organoleptik Hemiselulosa Tongkol Jagung (Zea mays L.)

\begin{tabular}{ll}
\hline Pengujian Organoleptik & Hasil Uji \\
\hline Bentuk & Granul \\
Warna & Coklatmuda \\
Rasa & Tidakberasa \\
Bau & Tidakberbau \\
\hline
\end{tabular}

Tabel 4. Hasil PSA Mikropatikel Hemiseluosa Tongkol Jagung

\begin{tabular}{llll}
\multicolumn{4}{c}{ Tabel 4. Hasil PSA Mikropatikel Hemiseluosa Tongkol Jagung } \\
\hline No & Formula & $\begin{array}{l}\text { Ukuran mikropartikel } \\
(\mu \mathrm{m})\end{array}$ & $\begin{array}{l}\text { PDI } \\
(\mu \mathrm{m})\end{array}$ \\
\hline 1 & Formula $1=100 \mathrm{mg}$ hemiselulosa & 0,45336 & 0,00105 \\
2 & Formula $2=200 \mathrm{mg}$ hemiselulosa & 0,63593 & 0,0009 \\
3 & Formula $3=300 \mathrm{mg}$ hemiselulosa & 0,71732 & 0,00108 \\
4 & Formula 4= 400 mg hemiselulosa & 0,89322 & 0,00105 \\
5 & Formula 5= 500 mg hemiselulosa & 0,91857 & 0,00112 \\
\hline
\end{tabular}

Untuk pemeriksaan distribusi ukuran partikel dilakukan dengan PSA (Particle Size Analyzer). Dari hasil pemeriksaan distribusi ukuran partikel yang dilakukan, perbedaan ukuran partikel dipengaruhi oleh jumlah 
hemiselulosa yang digunakan sebagai pembentuk dinding mikrokapsul [14]. Hasil yang diperoleh menunjukkan bahwa mikrokapsul yang dihasilkan untuk tiap formula menghasilkan ukuran berbeda-beda. Semakin besar jumlah dari polimer yang digunakan maka semakin tebal penyalut yang menyelubungi Metronidazol sehingga ukuran mikrokapsul yang dihasilkan semakin besar [15]. Dari hasil menunjukkan bahwa formula tersebut memiliki ukuran sebagai mikropartikel yang sesuai dan nilai indeks polidispersitas (PDI) yang sangat kecil. Indeks polidispersitas merupakan suatu data nilai analisa kumulatif dari dua parameter (ukuran dan jumlah) yang tidak berdimensi dan berskala dimana nilainya yang lebih kecil dari 0,05 menunjukkan sampel memiliki distribusi ukuran yang sempit dan homogen (monodisperse), sedangkan nilainya yang lebih besar dari 0,7 menujukkan bahwa sampel memiliki distribusi ukuran yang sangat luas (polidisperse) [16].

Berdasarkan analisis data menggunakan SEM, diperoleh struktur hemiselulosa dari tongkol jagung, morfologi dan tofologi struktur. Dapat dilihat pada gambar 4.1 berikut :

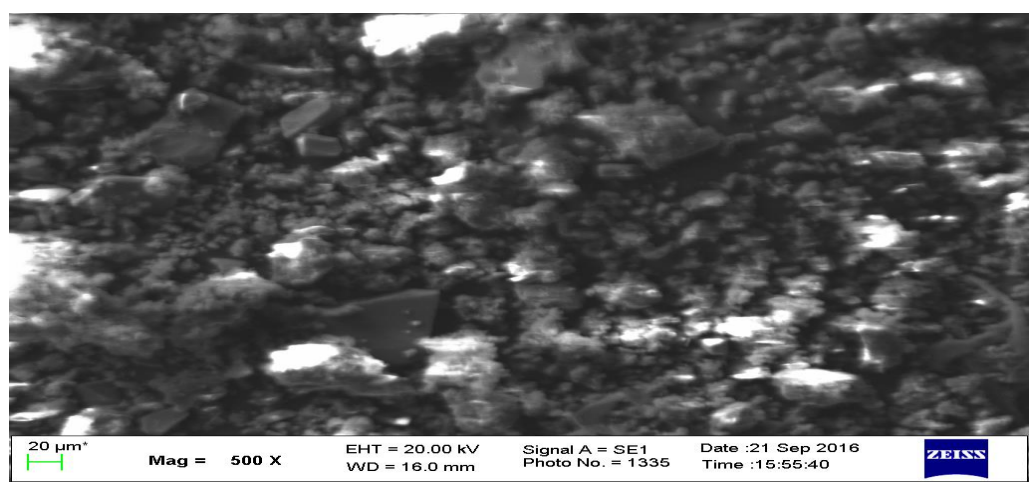

Gambar 1. SEM hemiselulosa tongkol jagung perbesaran $500 \mathrm{x}$

\subsection{Uji SEM (Scan Electro Magnetic) Mikropartikel Hemiselulosa}

Berdasarkan analisis menggunakan SEM, diperoleh struktur mikropartikel hemiselulosa dapat dilihat pada gambar 4.2.

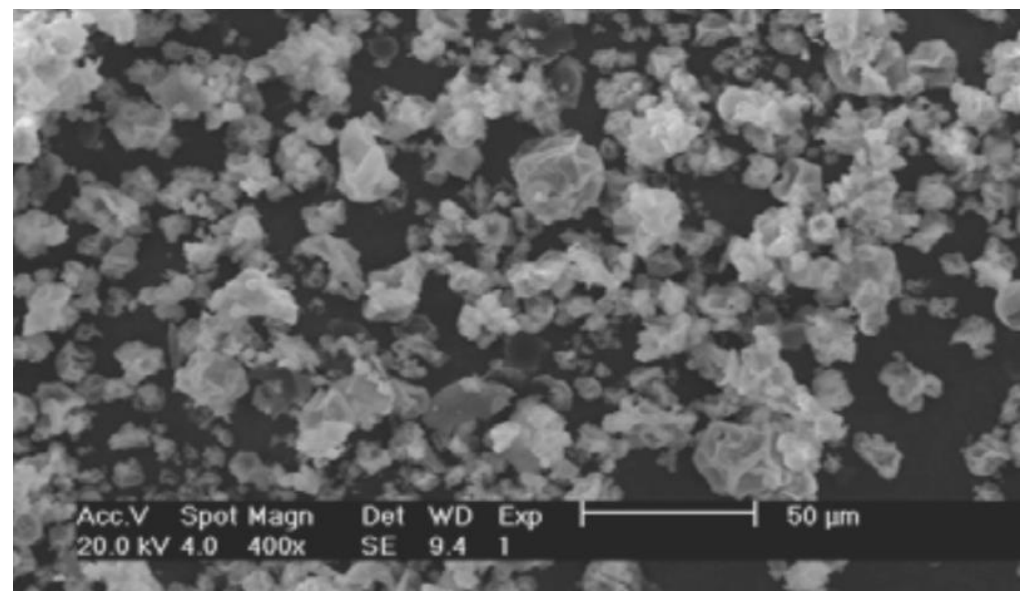

Gambar 2. SEM mikropartikel perbesaran 400x

Pada gambar 4.2 pada perbesaran 400x menunjukkan struktur mikropartikel hemiselulosa sudah terlihat lebih kecil.

Analisis FTIR dilakukan dengan menggunakan metode pellet KBr. Puncak-puncak karakteristik yang nampak pada spektrum FTIR dari mikropartikel yang diinterpretasi. 
ФSHIMADZU

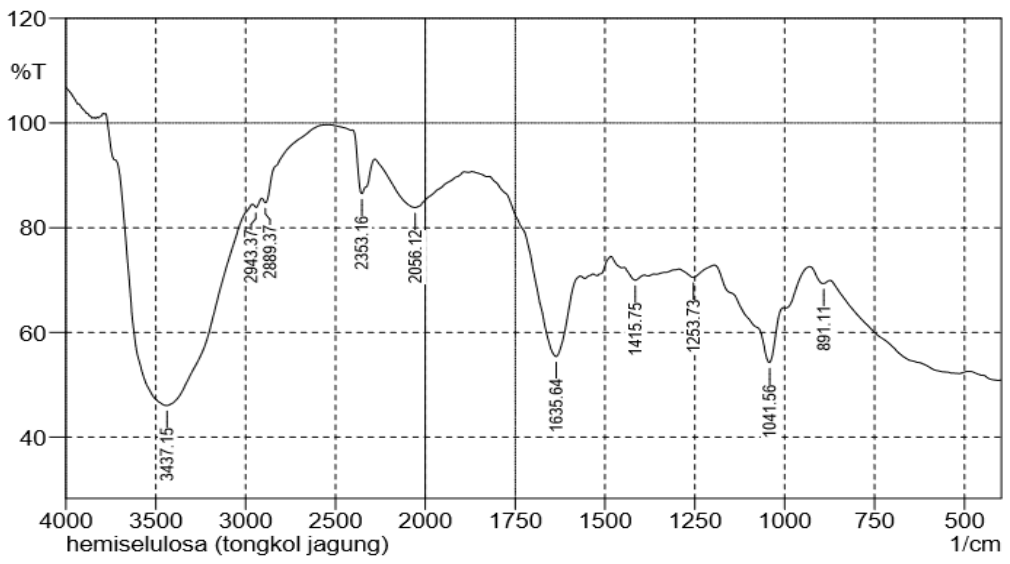

Grafik 3. Serapan FTIR Hemiselulosa Tongkol Jagung (Hasil isolasi)

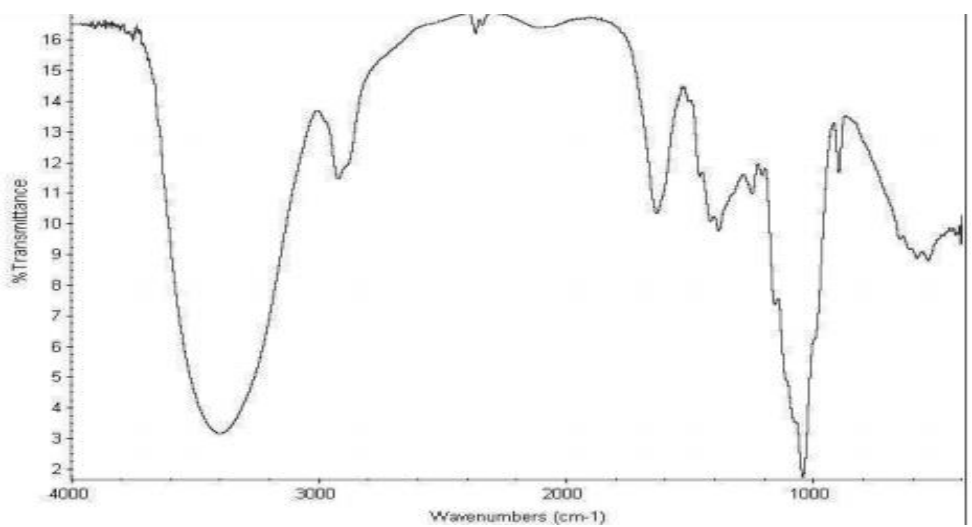

Gambar 4. Grafik Serapan FTIR Hemiselulosa Tongkol Jagung [17]

Tabel 5. Hasil FTIR Hemiselulosa Tongkol Jagung

\begin{tabular}{lllll}
\hline No. & Hasil FTIR penelitian & & Hasil FTIR penelitian sebelumnya \\
& & & & \\
\hline & Panjang gelombang & Gusus fungsi & Panjang gelombang & Gugus fungsi \\
1 & $3437,15 \mathrm{~cm}^{-1}$ & $\mathrm{OH}$ & $3400 \mathrm{~cm}^{-1}$ & $\mathrm{OH}$ \\
2 & $2943,37 \mathrm{~cm}^{-1}$ & $\mathrm{CH}$ & $2900 \mathrm{~cm}^{-1}$ & $\mathrm{CH}$ \\
3 & $1635,64 \mathrm{~cm}^{-1}$ & $\mathrm{C}=\mathrm{O}$ & $1700 \mathrm{~cm}^{-1}$ & $\mathrm{C}=\mathrm{O}$ \\
4 & $1041,56 \mathrm{~cm}^{-1}$ & $\mathrm{C}-\mathrm{OH}$ & $1044 \mathrm{~cm}^{-1}$ & $\mathrm{C}-\mathrm{OH}$ \\
5 & $891,11 \mathrm{~cm}^{-1}$ & $\mathrm{C}-\mathrm{C}$ & $940 \mathrm{~cm}^{-1}$ & $\mathrm{C}-\mathrm{C}$ \\
\hline
\end{tabular}

Dari hasil serapan Spektrofotometri (FTIR) yang diperoleh menunjukkan bahwa gugus fungsi yang terdapat pada hemiselulosa tongkol jagung hasil isolasi hamper sama dengan gugus fungsi yang terdapat pada struktur kimia hemiselulosa pada peneliti terdahulu. 


\section{Kesimpulan}

Hemiselulosa dapat dimanfaatkan sebagai bahan pembuatan mikrokapsul yang baik dan telah memenuhi evaluasi dan karakteristik hemiselulosa. Ukuran mikropartikel terkecil terdapat pada $F(1)$ yaitu $0,45336 \mu m$. Hasil FTIR menunjukkan gugus fungsi memberikan arah pada mikropartikel hemiselulosa, serta hasil SEM menunjukkan partikel memiliki rongga dan pori sehingga baik digunakan sebagai sediaan mikroenkapsulasi.

\section{Ucapan Terima Kasih}

Penulis mengucapkan terima kasih kepada Laboratorium Terpadu UMN Alwashliyah, Laboratorium Penelitian Fakultas Farmasi Sumatera Utara yang telah banyak membantu penulis dalam menyelesaikan penelitian ini.

\section{Daftar Pustaka}

[1] Deasy, P.B (1984). Microencapsulation and related drug Proces, Marcele Dekker, Inc, New York. 1- 289

[2] Martin, A., Swarbrick, J., dan Cammarata, A. (1993). Dasar-dasar farmasi fisik dalam ilmu farmasetik edisi ketiga. Jakarta: Universitas Indonesia UI Press.

[3] Richana, N., P. Lestina dan T.T. Irawadi. (2012). Karakterisasi lignoselulosa:xilan dari limbah tanaman pangan dan pemanfaatannya untuk pertumbuhan bakteri RXA III-5 penghasil xilanase. J. Penelitian Pertanian

[4] BPS, Badan Pusat Statistik. (2015). Hasil survey Tanaman Pangan Statistik Padi dan palawija Tahun 2015.Artikel.

[5] Anonim ${ }^{\text {c. }}$ (2015).Jagung (online),http://id.wikipedia.org/wiki/Jagung. Diakses Pada Tanggal 3Juni 2015.

[6] Richana, N. (2010). Tepung Jagung Termodifikasi Sebagai Pengganti Terigu. Warta Penelitian dan Pengembangan Vol. 32 (1) : 6

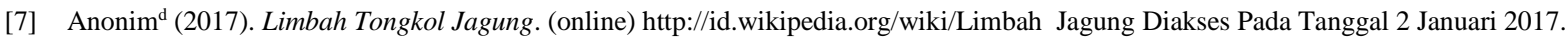

[8] Amrutkar J.R, Guttani S.G (2009). Chitosan - Chondroitin Sulfat Matrix Tablet for Colon Spesific Delivery of Indometacin.APPs.PharmSciTech.Jun ; 10(2); 670- 617.

[9] Dumitriu, S. (2010).Polysaccharides : Structural Diversity dan Functional Versatility, new York : Marcel Dekker, Hal. 10,30,33533

[10] Anderson, P.G, Knoben, James E, Troutman W.G (2001). Handbook Clinical Drug Data.10 ${ }^{\text {th }}$ edition.

[11] Lachman, L., Lieberman, H.A., danKanig, J.L., (1994), Teori dan Praktek Industri Farmasi II, diterjemahkan oleh Siti Suyatmi dan Iis Aisyah, Edisi III, 934-935, UI Press, Jakarta

[12] Pavia, L.D. (1979). Introduction to spectroscopy a Guide for students of Organic Chemistry. Philadelphia: Saunders Collage

[13] Muchlisyam, Sumaiyah, (2016). Aplication of Corn Cobs Hemiselulose Microparticle, Carrier With Insulin as Model. Der Pharma Chemica, (2016). 8 (19) : $632: 641$.

[14] Shargel, L., dan Yu, A. (2005). Applied Biopharmaceutics and Pharmakokinetics. 4th ed. Mc Graw-Hill Companies.Jakarta. Air Langga University Press. Hal. 86-95

[16] Karaaslan,A.M., Tshabalala, M.A., Buschle, D.G. (2010).Wood Hemisellulose/Chitosan-Basedsemi-Interpenetrating Networks Hydrogels: Mechanical, Swelling and Control Drug Release Properties. Journal Bioresources.5 (2), pp. 1036-1054

[17] Silva E.A et al, 2012. Xylan, a promising Hemicellulose for Pharmaceutical Use, Product and Application of Biopolymers. INTECH. Halaman 68. 